\title{
Physico-Chemical Characteristics of Spodumene Concentrate and Its Thermal Transformations
}

\author{
Allen Yushark Fosu ${ }^{1}$, Ndue Kanari ${ }^{1}$ (D), Danièle Bartier ${ }^{1}$, Harrison Hodge ${ }^{2}$ (D) James Vaughan ${ }^{2}$ \\ and Alexandre Chagnes $1, * \mathbb{D}$ \\ 1 Université de Lorraine, CNRS, GeoRessources, F-54000 Nancy, France; allen.fosu@univ-lorraine.fr (A.Y.F.); \\ ndue.kanari@univ-lorraine.fr (N.K.); daniele.bartier@univ-lorraine.fr (D.B.) \\ 2 School of Chemical Engineering, The University of Queensland, Brisbane, QLD 4072, Australia; \\ h.hodge@uq.edu.au (H.H.); james.vaughan@uq.edu.au (J.V.) \\ * Correspondence: alexandre.chagnes@univ-lorraine.fr; Tel.: +33-372-744-544
}

Citation: Fosu, A.Y.; Kanari, N.; Bartier, D.; Hodge, H.; Vaughan, J.; Chagnes, A. Physico-Chemical Characteristics of Spodumene Concentrate and Its Thermal Transformations. Materials 2021, 14, 7423. https://doi.org/10.3390/ ma14237423

Academic Editor: Giuseppe Cruciani

Received: 4 October 2021

Accepted: 1 December 2021

Published: 3 December 2021

Publisher's Note: MDPI stays neutral with regard to jurisdictional claims in published maps and institutional affiliations.

Copyright: (C) 2021 by the authors. Licensee MDPI, Basel, Switzerland. This article is an open access article distributed under the terms and conditions of the Creative Commons Attribution (CC BY) license (https:/ / creativecommons.org/licenses/by/ $4.0 /)$.

\begin{abstract}
Spodumene concentrate from the Pilbara region in Western Australia was characterized by X-ray diffraction (XRD), Scanning Electron Microscope Energy Dispersive Spectroscopy (SEM-EDS) and Mineral Liberation Analysis (MLA) to identify and quantify major minerals in the concentrate. Particle diameters ranged from 10 to 200 microns and the degree of liberation of major minerals was found to be more than $90 \%$. The thermal behavior of spodumene and the concentration of its polymorphs were studied by heat treatments in the range of 900 to $1050{ }^{\circ} \mathrm{C}$. All three polymorphs of the mineral $(\alpha, \gamma$ and $\beta$ ) were identified. Full transformation of the $\alpha$-phase was achieved at $975{ }^{\circ} \mathrm{C}$ and $1000{ }^{\circ} \mathrm{C}$ after 240 and 60 min treatments, respectively. SEM images of thermally treated concentrate revealed fracturing of spodumene grains, producing minor cracks initially which became more prominent with increasing temperature. Material disintegration, melting and agglomeration with gangue minerals were also observed at higher temperatures. The metastable $\gamma$-phase achieved a peak concentration of $23 \%$ after $120 \mathrm{~min}$ at $975{ }^{\circ} \mathrm{C}$. We suggest $1050{ }^{\circ} \mathrm{C}$ to be the threshold temperature for the process where even a short residence time causes appreciable transformation, however, $1000{ }^{\circ} \mathrm{C}$ may be the ideal temperature for processing the concentrate due to the degree of material disintegration and $\alpha$-phase transformation observed. The application of a first-order kinetic model yields kinetic parameters which fit the experimental data well. The resultant apparent activation energies of 655 and $731 \mathrm{~kJ} \mathrm{~mol}^{-1}$ obtained for $\alpha$ - and $\gamma$-decay, respectively, confirm the strong temperature dependence for the spodumene polymorph transformations.
\end{abstract}

Keywords: spodumene concentrate; thermal transformation; activation energy; first-order kinetics; morphological changes; physicochemical properties

\section{Introduction}

Lithium is undergoing important investigations in order to meet its worldwide stable supply as this element is now considered a critical metal by many countries. It is produced from salar brines or ores. The production from salar brines involves three major steps; evaporation, purification and precipitation. The recovery of the metal by this approach faces many challenges, including the delay in production due to solar evaporation and the presence of many impurities which demand the implementation of refining stages. The main interest of lithium production from salar brine comes from the low cost of the operations. However, the recent increase in the price of lithium has resulted in huge investments into lithium production from ores.

Lithium-Cesium-Tantalum (LCT) pegmatites are the main source of lithium as well as a rich source of tantalum and cesium as they contain spodumene, columbite-tantalite and pollucite, respectively [1]. They may also contain lepidolite, petalite, eucryptite and amblygonite as lithium sources. Muscovite, albite, quartz and feldspar are common minerals that are in close association with LCT; often considered as gangue but may be 
a by-product of lithium processing. In spite of the high processing cost from ores, the increasing demand and its price make it economically viable. About half of the lithium produced is now obtained from ores [2] and spodumene $\left(\mathrm{LiAlSi}_{2} \mathrm{O}_{6}\right)$ stands out as the most significant ore-type due to the high lithium content (about $4 \%$ ) in its pure state as well as its ease of processing.

Spodumene belongs to the clinopyroxene group, occurring naturally as $\alpha$ monoclinic polymorph which is immune to chemical attack due to its compact nature. In this form, lithium and aluminum sit at the M2 and M1 octahedral sites respectively, whilst silicon is hosted at the middle of the tetrahedron. The octahedral parts through the sharing of common oxygen atoms, bridge to form chains. The octahedral chains are parallelly arranged to $\mathrm{Si}$ in the tetrahedron through $\mathrm{O}-\mathrm{Si}-\mathrm{O}$ ionic bond with the $\mathrm{Li}$ and $\mathrm{Al}$ atoms. Its original space group is $\mathrm{C} 2 / \mathrm{c}$ and in this form, lithium bonds with six atoms of oxygen; with a pair of oxygen atoms having a definite $\mathrm{Li}-\mathrm{O}$ bond length of 2.120, 2.267 and $2.281 \AA$ [3]. At pressures of around $3.2 \mathrm{GPa}$, the original stable space group (C2/c) may change to $\mathrm{P} 21 / \mathrm{c}$ upon reversible transition [4-6] and assumes cell parameters of $a=9.471 \AA, b=8.400 \AA$, $c=5.223 \AA, \alpha=\gamma=90.0$ degrees and $\beta=110.2$ degrees.

$\beta$-spodumene, another polymorph of the mineral consists of two separate tetrahedron structures which are joined in a three-dimensional form with their central parts hosting aluminum or silicon [7]. Lithium in this phase is located between the cavity of five-member rings, formed by the individual tetrahedron. Zeolite-like channels created from the fivemember rings run parallel to the (100) or (010) planes [8]. The zeolite-like channels which are parallel to the $a$ and $b$ axis are comparatively larger and account for the tremendous ion-exchange capacity of $\beta$-spodumene during roasting [8]. It has the space group $\mathrm{P}_{3}{ }_{3}{ }_{1} 2$ with cell parameters $a=b=7.534 \AA$ and $c=9.158 \AA$ [7]. An intermediary metastable $\gamma$-phase which transforms to the $\beta$-phase upon continuous heating has also been identified. It has a hexagonal symmetry where $\mathrm{Si}$ and $\mathrm{Al}$ sit at the middle of the tetrahedrons. This polymorph of the mineral starts appearing between $700{ }^{\circ} \mathrm{C}$ and $900{ }^{\circ} \mathrm{C}$ during the thermal process.

Lithium is sequentially extracted from spodumene via three processes namely decrepitation, roasting to form soluble salt by sulfation, carbonation, chlorination or fluorination [9]; followed by water leaching of the products of roasting to form an aqueous lithium solution. During decrepitation, the mineral is roasted at high temperatures (above $800^{\circ} \mathrm{C}$ ) to convert the monoclinic $\alpha$ form to the tetragonal $\beta$ form. The conversion of $\alpha$ to the $\beta$-phase leads to volumetric enlargement of the lattice; making the $\beta$-spodumene structure comparatively open for the chemical attack. A series of investigations were conducted to enhance the decrepitation process [3,10,11] using different heating techniques [12] as well as optimizing the extraction efficiency at different leaching conditions [12-16].

The Pilbara region in Western Australia has a rich deposit of LCT-spodumene-type pegmatite ore where lithium concentrate is produced and exported. Numerous companies are also on the move to mine this type of ore. The need to understand the physicochemical characteristics of the concentrate prior to beneficiation is crucial for efficient lithium recovery. This study aims to characterize that concentrate as well as understand its thermal transformation behaviors.

\section{Materials and Methods}

\subsection{Spodumene Concentrate Preparation}

The concentrate was achieved by several unit operations including crushing, grinding, gravity separation (Dense Media Separation (DMS)) and froth flotation. The ore was crushed with primary and secondary crushers to particle size of $32 \mathrm{~mm}$ onto a stockpile. It was then fed into High-Pressure Grinding Rolls to reduce the size further to $3.35 \mathrm{~mm}$. This was followed by a two-stage DMS which led to the recovery of course spodumene concentrate. The lower grade unrecovered material was fed into a ball mill which reduced the size to 115 microns prior to tantalite recovery as a by-product via gravity separation. The spodumene-containing fraction was conditioned at a little above $50 \%$ pulp density in a neutral $\mathrm{pH}$ using sodium oleate as collector. Spodumene in the conditioned material 
was floated at $30 \%$ pulp density and gangue minerals rejected to tailings. This led to $85 \%$ recovery and an upgraded concentrate of about $4.6 \% \mathrm{Li}_{2} \mathrm{O}$. The floated material then entered the cleaning stage yielding the concentrate. The concentrate produced as described above was provided by Pilbara Minerals for the study. It consisted of damp, fine-grained material with a significant portion composed of large agglomerated particles that were several centimeters in diameter. The bulk of the material was greenish-brown in color. Breaking apart the agglomerate particles revealed a light grey material. An image of the bulk and grey material is shown in Figure 1. The different coloration observed may be due to the presence of varying concentrations of $\mathrm{Fe}$ and $\mathrm{Mn}$ which substitute for $\mathrm{Al}$ at the various locations. Spodumene is usually associated with Fe which gives it a greenish color. At lower Fe concentration resulting from substitution by Mn, a grey/white color is observed as in this case [17].

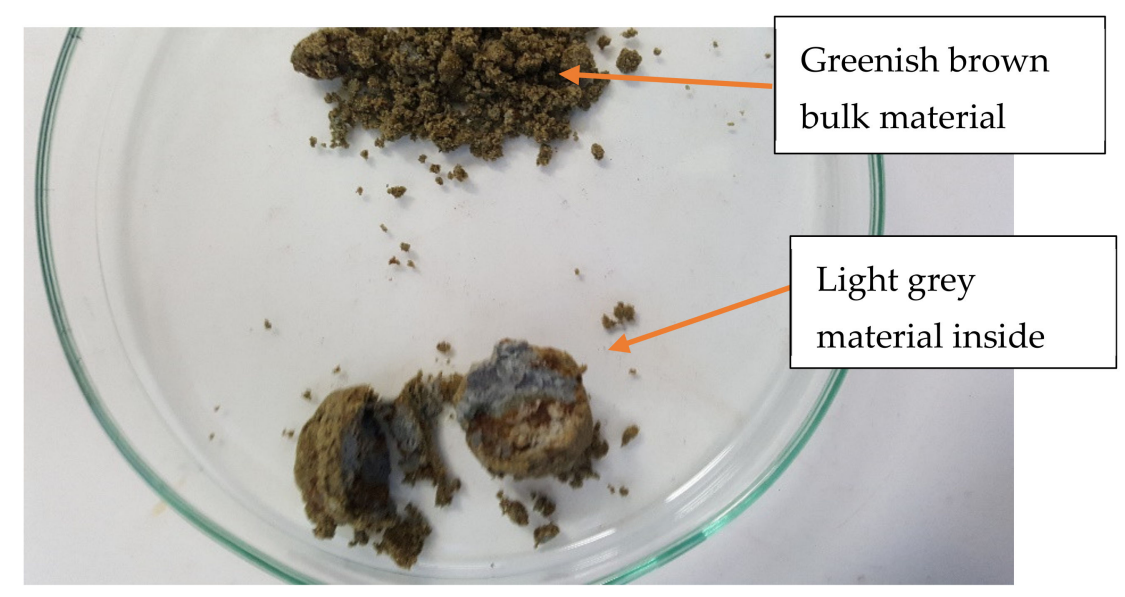

Figure 1. Optical image showing both the bulk and grey material contained in agglomerate particles.

The as-received sample was formed into a cone and tarp and then cut into approximately two portions. A portion was dried at $60{ }^{\circ} \mathrm{C}$ for $48 \mathrm{~h}$ after which it was passed through a $3.25 \mathrm{~mm}$ screen to break agglomerate particles. The dried material was split into eight subsamples using a rotary splitter. These subsamples were further split using a riffle splitter to generate representative samples of about $1 \mathrm{~kg}$ in mass. A representative subsample of the other moist portion was sectioned off by pie splitting which was used to determine the elemental and mineral composition.

\subsection{Particle Size Distribution}

A representative subsample of the dried material was used to determine the particle size distribution. Approximately, $15 \mathrm{~g}$ of the sample was slurred in a $1 \mathrm{~L}$ stirred baffled reactor containing water. A small amount of detergent was added to enhance breaking the agglomerates and reduce hydrophobicity. This slurry was then sampled using a pipette across the entire depth of the reactor. Sample was transferred to a Malvern Mastersizer for particle size analysis. A total of 5 repeats with two additional rejected runs were completed.

\subsection{Thermal Treatment}

Samples were roasted at varying temperatures from 900 to $1050{ }^{\circ} \mathrm{C}$ at $25^{\circ} \mathrm{C}$ intervals and residence times of 7.5, 15, 30, 60, 240 and $480 \mathrm{~min}$. A cylindrical quartz crucible was used to hold the sample for heating using a Carbolite Gero electric furnace which heats up to $1500{ }^{\circ} \mathrm{C}$. The furnace provides a constant homogeneous heating $20 \mathrm{~cm}$ at its center, therefore, samples placed in the middle have constant temperature throughout the experiment. It was calibrated such that the extent of deviation from the set temperature was $\pm 5{ }^{\circ} \mathrm{C}$ throughout the study. The reactor was made of quartz tube placed inside the furnace and the whole setup was operated in air with a flow rate of $25 \mathrm{~L} / \mathrm{h}$. The furnace was preheated for $60 \mathrm{~min}$ to achieve a steady temperature for samples to attain the 
reaction temperature within the shortest possible time. This was important for accurate time measurements. Residence time was measured immediately after the sample was introduced into the furnace until the specified time elapsed. Samples were weighed and some portions pulverized with an agate mortar prior to XRD analysis and the other portions kept for SEM analyses.

\subsection{XRD Analyses}

X-ray diffraction (XRD) patterns of samples were collected at ambient temperature, using a $\mathrm{CuK} \alpha$ radiation D2 Phaser Bruker diffractometer which is equipped with LYNXEYE detector under $30 \mathrm{kV}$ and $10 \mathrm{~mA}$. The analyses were performed on the powdered samples which have non-oriented flat plates. XRD patterns were recorded between $2 \theta=2.5^{\circ}$ and $2 \theta=70^{\circ}$ at a scan step of $2 \theta=0.02^{\circ}$ and step exposure time of $1 \mathrm{~s}$. Semi-quantitative relative abundances of the phases were estimated using the EVA@ software coupled with the PDF2 database of the International Centre for Diffraction Data. The semi-quantitative analyses were performed based on the pattern's relative heights and I/I $\mathrm{I}_{\text {cor }}$ values by assuming that all crystalline phases were detected and their sum was $100 \%$.

\subsection{SEM-EDS Analyses}

Two preparation procedures were employed on samples before analysis. First, powdered samples were glued on a graphite support and the surfaces covered with a thin layer of carbon. The second was performed by placing the powdered sample in an epoxy resin and allowed to stand until they hardened. Surfaces of the hardened materials were polished and ultrasonically cleaned with deionized water to achieve a highly polished surface. The surfaces of the samples prepared by the two approaches were coated with a thin film of carbon. The coating is to enhance good electrical conductivity during analysis.

\subsection{Mineral Liberation Analysis}

Mineral Liberation Analysis (MLA) used in this study makes use of BSE images and point-generated X-ray signals coupled with modern image and pattern identification for its measurements $[18,19]$. The samples were prepared by allowing the untreated concentrate to stand in resin to harden, followed by surface polishing as in Section 2.5 above. The prepared samples were then subjected to the MLA. Grain particles touching each other due to their settling mode in the resin were detected by DataView with its online program software package and then separated from each other using the shadow/boundary identification procedure. This was to ensure that, all grain particles in the sample were well separated from each other to avoid possible interference which may lead to errors in liberation results and mineral phase identification. Mineral phase identification was achieved by comparing elemental composition X-ray analysis with a standard database. Here, particles of the concentrate (which are in the resin) were divided into their individual mineral grains and their boundaries demarcated using their average BSE grey level. The device performs a systematic point $X$-ray elemental map which is associated with specific grains based on the differences in the grey level from the BSE map of the composite particles. The $\mathrm{X}$-ray elemental map generated is matched to the corresponding average atomic number (AAN) of each mineral for their identification. In situations where mineral identification uncertainties arise due to overlap of grey level or minerals of similar AAN, the area X-ray analysis detects these anomalies and with the help of $X$-ray mapping, these minerals are discriminated and identified. Data obtained on the minerals are then stored for presentation in MLA DataView software.

\subsection{X-ray Fluorescence (XRF) Microscopy and Inductively Coupled Plasma-Optical Emission Spectrometry (ICP-OES)}

The bulk assay for the sample was carried out by a commercial laboratory (ALS Environmental Testing, Stafford, QLD) by combining XRF and digestion/ICP-OES for major components and minor components, respectively. 


\section{Results and Discussion}

\subsection{Bulk Chemical Analysis}

The result of the elemental composition of the concentrate as oxides obtained from $\mathrm{XRF}$ and ICP-OES is presented in Table 1. The lithium concentration was determined as $2.14 \mathrm{wt} . \%$; consequently, the calculated lithium oxide and spodumene concentrations were $4.61 \mathrm{wt.} \%$ and $57.39 \mathrm{wt} . \%$ respectively. This is in close agreement with the $60.21 \mathrm{wt} . \%$ spodumenes indicated by the MLA result (Table 2) and $3 \mathrm{wt} . \%$ Li content in spodumene from the Pilbara region reported in the literature [17]. All elements identified are also in agreement with the previous investigation by Aylmore et al. [17] with the exception of $\mathrm{Ba}$ and Co which were not identified in this study.

Table 1. Elemental composition of concentrate determined by XRF and ICP-OES.

\begin{tabular}{|c|c|c|c|c|c|c|c|c|c|c|c|c|c|c|c|c|c|c|}
\hline Major & $\mathrm{Al}_{2} \mathrm{O}_{3}$ & $\mathrm{CaO}$ & $\mathrm{Cr}_{2} \mathrm{O}_{3}$ & $\mathrm{Fe}_{2} \mathrm{O}_{3}$ & $\mathrm{~K}_{2} \mathrm{O}$ & $\mathrm{MgO}$ & $\mathrm{MnO}$ & $\mathrm{Na}_{2} \mathrm{O}$ & $\mathrm{P}_{2} \mathrm{O}_{5}$ & $\mathrm{SO}_{3}$ & $\mathrm{SiO}_{2}$ & $\mathrm{TiO}_{2}$ & $\overline{L i}$ & Cs & $\mathbf{R b}$ & $\mathrm{Ta}$ & $\mathrm{Nb}$ & Sn \\
\hline $\begin{array}{l}\text { (wt.\%) } \\
\text { (ppm) }\end{array}$ & 20.79 & 1.72 & 0.03 & 4.29 & 1.26 & 1.30 & 0.32 & 1.14 & 0.33 & 0.15 & 61.31 & 0.10 & 2.14 & 116 & 1033 & 202 & 180 & 140 \\
\hline
\end{tabular}

Table 2. MLA modal mineralogy.

\begin{tabular}{ccc}
\hline Mineral & Formula & wt.\% \\
\hline Spodumene & $\mathrm{LiAl}_{\left(\mathrm{Si}_{2} \mathrm{O}_{6}\right)}$ & 60.21 \\
Pyrite & $\mathrm{FeS}_{2}$ & 0.13 \\
Quartz & $\mathrm{SiO}_{2}$ & 7.58 \\
Orthoclase & $\mathrm{KAlSi}_{3} \mathrm{O}_{8}$ & 4 \\
Albite & $\mathrm{NaAli}_{3} \mathrm{O}_{8}$ & 9.1 \\
Anorthite & $\mathrm{CaAl}_{2} \mathrm{Si}_{2} \mathrm{O}_{8}$ & 1 \\
Biotite & $\mathrm{KMg}_{2.5} \mathrm{Fe}^{2+} 0_{0.5 \mathrm{Ali}_{3} \mathrm{O}_{10}(\mathrm{OH})_{1.75} \mathrm{~F}_{0.25}}$ & 3.32 \\
Muscovite & $\mathrm{KAl}_{3} \mathrm{Si}_{3} \mathrm{O}_{10}(\mathrm{OH})_{1.9} \mathrm{~F}_{0.1}$ & 4.9 \\
Chlorite & $(\mathrm{Mg}, \mathrm{Fe})_{3}\left(\mathrm{Si}_{2} \mathrm{Al}_{4} \mathrm{O}_{10}(\mathrm{OH})_{2} \cdot(\mathrm{Mg}, \mathrm{Fe})_{3}(\mathrm{OH})_{6}\right.$ & 0.33 \\
Amphibole & $\mathrm{CaFeSi}_{2} \mathrm{O}_{6}$ & 7.3 \\
Spessartine & $\mathrm{Mn}_{2}+3 \mathrm{Al}_{2}\left(\mathrm{SiO}_{4}\right)_{3}$ & 0.61 \\
Tantalite-(Mn) & $\mathrm{MnTa}_{2} \mathrm{O}_{6}$ & 0.12 \\
Calcite & $\left.\mathrm{Ca}_{(\mathrm{CO}}\right)$ & 0.47 \\
Apatite & $\mathrm{Ca}_{5}\left(\mathrm{PO}_{4}\right)(\mathrm{F}, \mathrm{Cl}, \mathrm{OH})$ & 0.93 \\
\hline
\end{tabular}

\subsection{Mineralogy}

XRD spectra of the concentrate are shown in Figure 2. Spodumene, mica (muscovite and biotite), quartz, feldspars (orthoclase, albite, anorthite) and the amphiboles are the predominant minerals identified which are typical minerals of spodumene ore of Pilbara. XRD has become the common analytical tool for determining the mineral composition of samples, it has, therefore, been used with the support of other analytical techniques (MLA and EDS) for the finest detection of mineral assemblage in the concentrate.

The modal mineralogy identified by MLA with their concentrations are shown in Table 2. This result is consistent with the XRD analyses, however, spessartine, tantalite, calcite and apatite which appeared as trace minerals were not identified by XRD. An operator decision was made to take into account only minerals that present at least two diffraction peaks (the main and secondary peaks). Thus, minerals with a very low concentration and showing only their main peak, which was difficult to dissociate from the background noise, could have been neglected. This could result in some trace minerals unidentified by XRD contrary to MLA and EDS point analysis.

The results are in close agreement with the mineralogy of LCT-spodumene ore except with the presence of amphibole which is identified in this work. Elemental assay of the concentrate was also calculated by MLA and the results are presented in Table 3. Computing the oxides of these elements shows a close agreement with chemical analyses in Table 1. The results of this computation are shown in Table S1 of the Supplementary Material. 


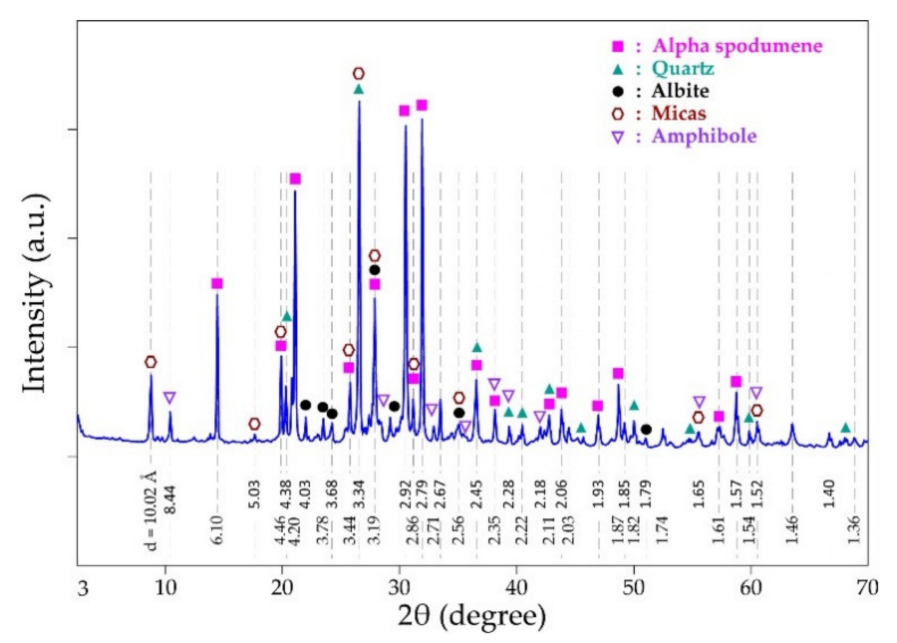

Figure 2. XRD patterns of spodumene concentrate.

Table 3. Calculated elemental assay from MLA.

\begin{tabular}{ccccccccccccccccc}
\hline $\mathbf{L i}$ & $\mathbf{A l}$ & $\mathbf{S i}$ & $\mathbf{C}$ & $\mathbf{S}$ & $\mathbf{F e}$ & $\mathbf{K}$ & $\mathbf{N a}$ & $\mathbf{T a}$ & $\mathbf{P}$ & $\mathbf{M n}$ & $\mathbf{M g}$ & $\mathbf{C a}$ & $\mathbf{C l}$ & $\mathbf{F}$ & $\mathbf{H}$ & $\mathbf{O}$ \\
\hline 1.96 & 11.58 & 29.47 & 0.06 & 0.07 & 2.0 & 1.34 & 0.76 & 0.09 & 0.17 & 0.22 & 0.5 & 1.97 & 0.02 & 0.09 & 0.04 & 49.39 \\
\hline
\end{tabular}

The particle size of the major minerals was also determined by MLA and the corresponding results are displayed in Figure 3. There are no significant differences between the particle sizes of the minerals in the concentrate. The grain sizes are small with the majority below 100 microns (d80 around 100 microns). At this particle size, the minerals are well liberated as the degree of liberation of all of them is above $90 \%$ (Figure 4 ). Spodumene is the most liberated mineral as its degree of liberation reaches nearly $99 \%$. It follows that the comminution conditions employed for processing this ore are good since they yield concentrate which can be easily processed for maximum lithium extraction, provided the spodumene itself does not passivate. A raw MLA data generated for obtaining Figure 4 is provided in Table S2 of the Supplementary Material.

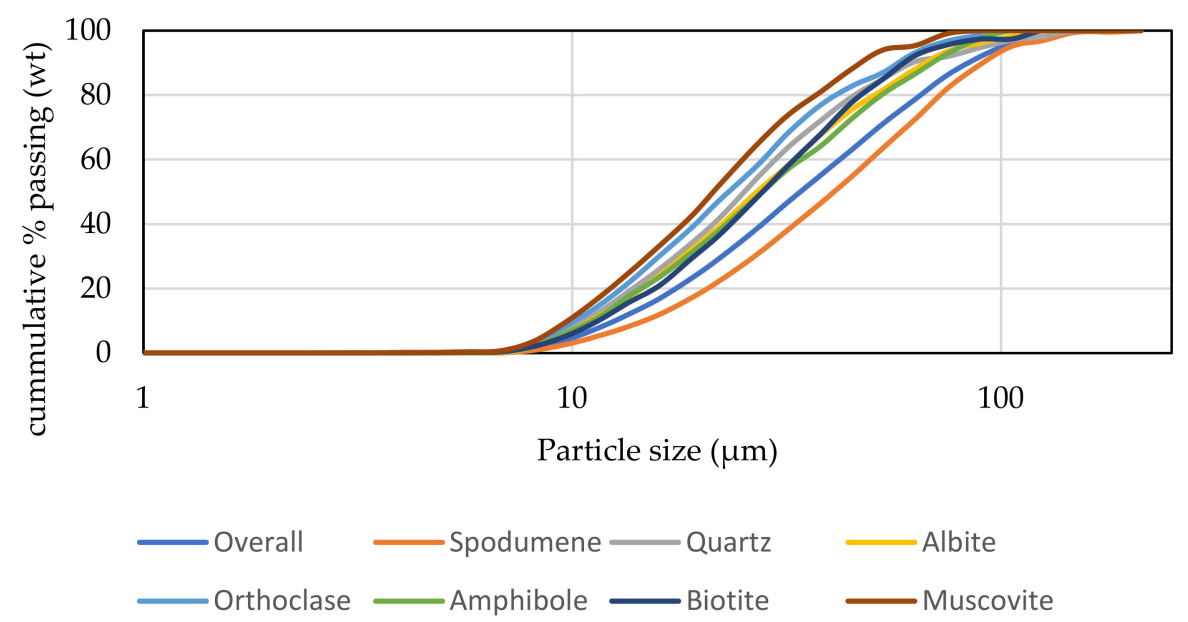

Figure 3. Mineral particle size determined by MLA. 


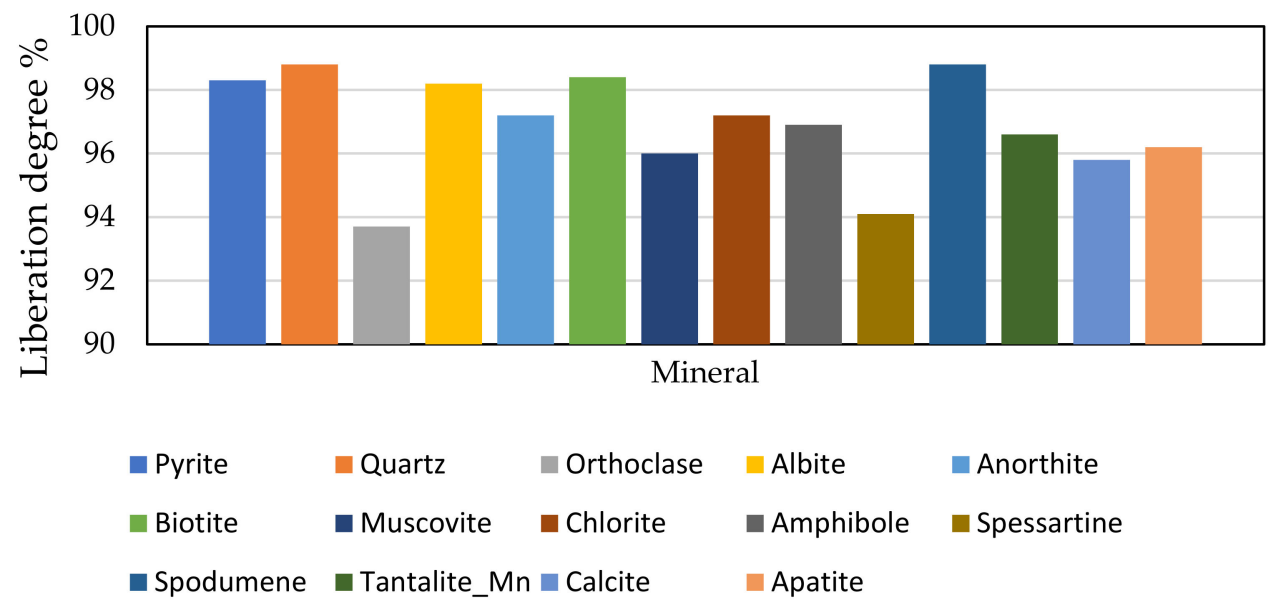

Figure 4. Degree of liberation of the main mineral phases.

\subsection{Morphology, Texture of Particles and Mineralogy}

Figure 5 shows the volume distribution and cumulative passing of the concentrate particles. Particle diameter ranges from 10 to 200 microns with about $68 \%$ of the total volume being 80 microns in diameter. The d50 and d 80 are indicated as 57 and 113 microns respectively. The $\mathrm{d} 80$ found is in close agreement with the 100 microns suggested earlier. Considering the higher liberation of spodumene grains, it may be indicated that, $\mathrm{d} 80$ of 113 microns and particle diameter of 80 microns are good comminution parameters for processing spodumene ore, particularly pegmatites ores of Pilbara origin.

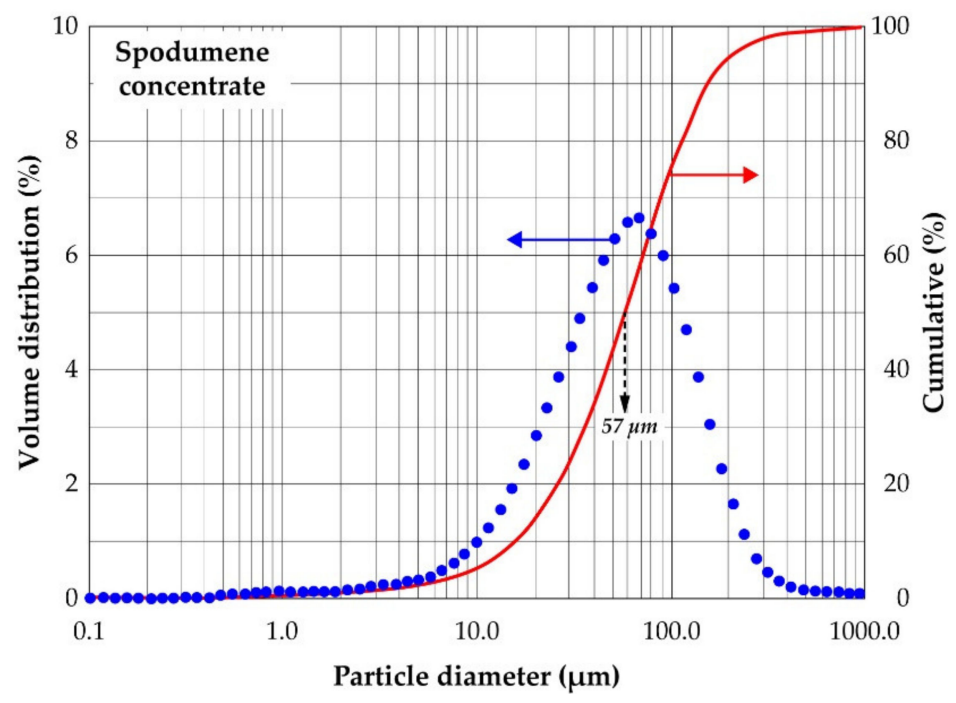

Figure 5. Volume distribution and cumulative passing of spodumene concentrate.

The BSE of the SEM was further used to investigate the morphology and texture of particles in the concentrate. It was coupled with EDS to determine the elemental composition at some points and hence the mineral composition. Figure 6 and Table 4 are the SEM photomicrograph and spot elemental composition of the concentrate respectively. It is observed (from Figure $6 a, b$ ) that, it is a well liberated coarse and loose material with varying particles of several microns in diameter; confirming earlier observation. 


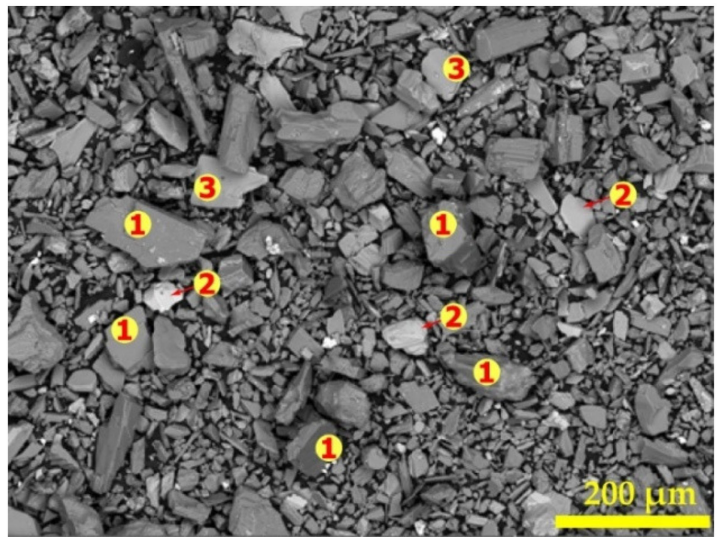

(a)

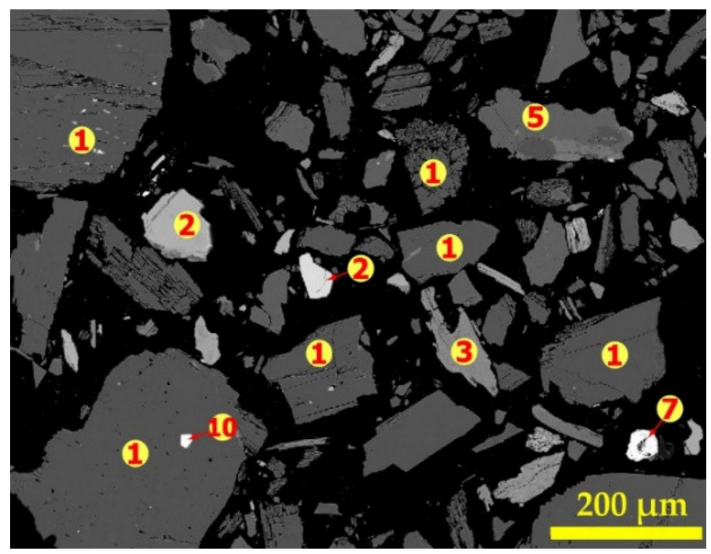

(c)

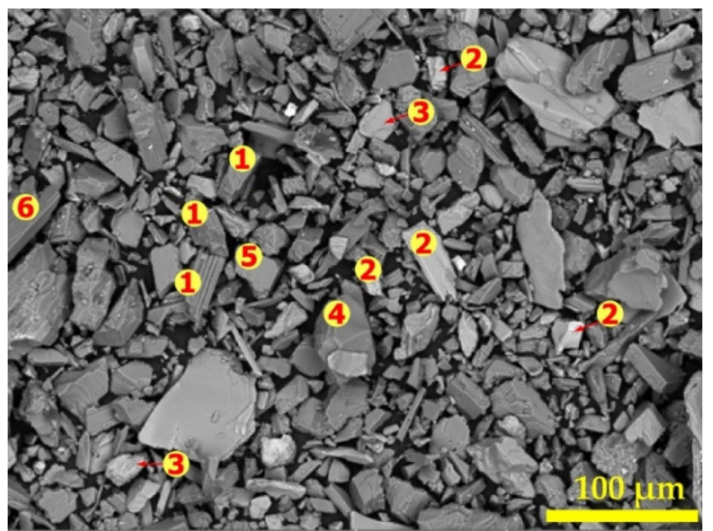

(b)

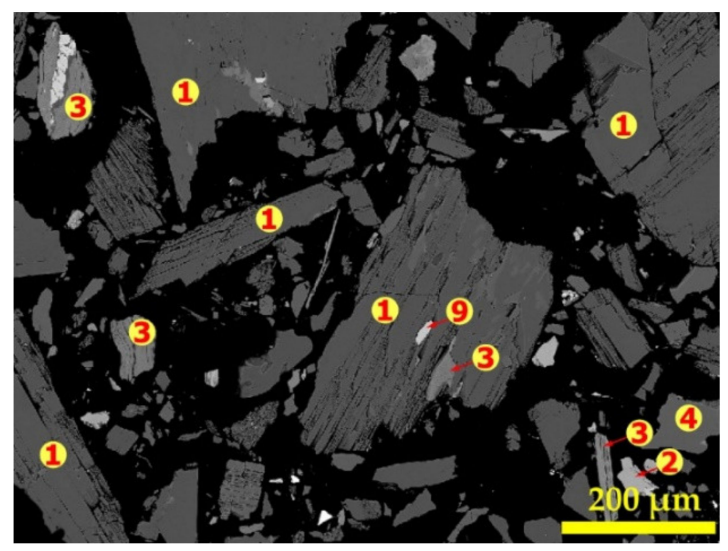

(d)

Figure 6. SEM of powdered (a,b) and polished samples (c,d) of concentrate. The numbers $(1$ to $7,9,10)$ indicate the locations of the elemental determination.

Table 4. Atomic percentage of mineral phases identified by SEM-EDS.

\begin{tabular}{|c|c|c|c|c|c|c|c|c|c|c|}
\hline Elements & Spot “1” & Spot “2" & Spot "3" & Spot "4" & Spot “5” & Spot "6" & Spot "7" & Spot "8" & Spot “9" & Spot "10" \\
\hline $\mathrm{O}$ & 64.7 & 60.9 & 54.4 & 66.7 & 61.9 & 61.6 & 60.1 & 67.3 & 56.6 & 67.8 \\
\hline $\mathrm{Al}$ & 11.5 & 5.2 & 4.1 & & 7.7 & 7.5 & 0.4 & & & \\
\hline $\mathrm{Si}$ & 23.6 & 16.8 & 16.1 & 33.3 & 23.3 & 23.2 & 0.6 & & & \\
\hline $\mathrm{Fe}$ & 0.2 & 6.2 & 2.2 & & & & 38.9 & 1.9 & & \\
\hline $\mathrm{Mg}$ & & 4.3 & 10.6 & & & & 0.1 & & & \\
\hline $\mathrm{Ca}$ & & 4.8 & & & 0.2 & & & & 20.2 & \\
\hline $\mathrm{Mn}$ & & 0.2 & & & & & & 8.5 & & \\
\hline $\mathrm{Na}$ & & 1.1 & & & 6.9 & 2.4 & & & & \\
\hline K & & 0.5 & 3.9 & & & 5.2 & & & & \\
\hline F & & & 8.6 & & & & & & 8.6 & \\
\hline P & & & & & & & & & 14.6 & \\
\hline $\mathrm{Nb}$ & & & & & & & & 12.1 & & \\
\hline $\mathrm{Ta}$ & & & & & & & & 10.3 & & 0.4 \\
\hline $\mathrm{N}$ & & & & & & & & & & 6.2 \\
\hline Sn & & & & & & & & & & 25.6 \\
\hline
\end{tabular}

Spodumene grains were identified using the $\mathrm{Si} / \mathrm{Al}$ ratio since EDS cannot detect the presence of lithium. The atomic ratio of $\mathrm{Si}$ to $\mathrm{Al}$ in spodumene is 2.0 hence all grains with spot elemental composition mainly of $\mathrm{Al}, \mathrm{Si}, \mathrm{O}$ and $\mathrm{Si} / \mathrm{Al}$ ratio of approximately 2.0 corresponds to spodumene. All spots indicated " 1 " are identified as spodumene. Figure $6 c, d$ confirm that spodumene is a coarse, dense, crystalline solid with a smooth surface, however, scratches were observed on some grains, which may be due to abrasion 
during comminution. It suggests that spodumene is a hard mineral that resists wear and tear except when in contact with a harder material. This is confirmed by its relatively high 6.5 to 7.0 value on the Mohs scale of mineral hardness. Spodumene is the major mineral found in the concentrate. It is well liberated but with few mineral associations. Spot "2" has a complex composition with $\mathrm{Fe}, \mathrm{Mg}, \mathrm{Ca}, \mathrm{Al}, \mathrm{Si}, \mathrm{O}$ as the major elements but with varying concentrations at different spots. We attribute these grains to the amphibole group of minerals as indicated in XRD spectra due to the higher concentration of $\mathrm{Fe}, \mathrm{Mg}$ and $\mathrm{Ca}$ at some spots. We could not attribute them to the mica group since the mica group identified by MLA in the concentrate are muscovite and biotite which all contain $\mathrm{K}$ in their chemistry but $\mathrm{K}$ is absent at these spots. Spots identified as amphibole do not have specific color but ranges from light gray to white depending on the concentration of heavy metals that may be present. The micas (muscovite and biotite) are identified by spot 3 where there is an appreciable higher concentration of K. Spots " 4 " are composed mainly of $\mathrm{Si}$ and $\mathrm{O}$ with an $\mathrm{O} / \mathrm{Si}$ ratio of approximately 2 and therefore identified as quartz. Spots " 5 " and " 6 " have a complex composition of $\mathrm{Ca}, \mathrm{K}$ and $\mathrm{Na}$ and are linked to the feldspars, specifically, alkali feldspars and anorthite. We specifically identify spot " 5 " as albite due to the high concentration of $\mathrm{Na}$ at these areas and spots " 6 " as other feldspars. Hematite was not identified by XRD nor MLA but Spot "7" is identified as such based on the composition. It is composed mainly of $\mathrm{Fe}$ and $\mathrm{O}$ with an $\mathrm{O} / \mathrm{Fe}$ ratio of approximately 1.5, confirming its identity. Tantalite and apatite which are typical of LCT-spodumene ore of the Pilbara region are also identified at spot " 8 " and "9", respectively. The standard deviations calculated for atomic percent obtained on some mineral grains in the concentrate are shown in Tables S3-S9. Spot "10" is composed of Sn, Ta, N and O. Though the identification of Sn by EDS is a confirmation of elemental composition in Table 1, we could not link the identity of this spot to any mineral since its composition did not match with any. We treat it as an impurity that is locked up in the spodumene grain. All major minerals in the concentrate were identified using spot elemental identification by EDS, confirming XRD and MLA analytical results. Raw data (elemental spectrum with their corresponding intensities, weight percent, etc.) generated by SEM-EDS instrument for mineral phases identified can be found in Figures S1-S8 and Tables S10-S17. Other elements such as Cr, $\mathrm{Ti}, \mathrm{F}, \mathrm{Th}, \mathrm{Sn}, \mathrm{Zn}, \mathrm{Cu}, \mathrm{Ni}, \mathrm{V}$, and $\mathrm{S}$ were also identified which are associated with the fine inclusion of some minerals. Though $\mathrm{Ta}, \mathrm{Nb}, \mathrm{Sn}$ and other valuable metals were observed, their concentrations are too low to be extracted in an economical manner.

\subsection{Morphological Changes in Spodumene during Thermal Treatment}

The morphological changes in the spodumene grain during decrepitation are of great importance since it gives an indication of the extent of structural changes and openness of the mineral for chemicals to interact with lithium atoms. Changes in the morphology of spodumene grains were studied on the residues treated at 900, 950, 1000 and $1050{ }^{\circ} \mathrm{C}$ using the BSE of SEM coupled with EDS. Figure 7 gives the SEM images with spots analyzed by EDS for both polished and unpolished samples. There are cracks and disintegration followed by melting and agglomeration with increasing temperature (Figure $7 \mathrm{e}-\mathrm{h}$ ). At $900{ }^{\circ} \mathrm{C}$, micro-cracks are observed (Figure 7e) which becomes prominent at $950{ }^{\circ} \mathrm{C}$ (Figure 7f) such that at $1000{ }^{\circ} \mathrm{C}$ (Figure $7 \mathrm{~g}$ ), the spodumene grains had disintegrated and was well open for subsequent processes. From this observation, one may advise that $1000{ }^{\circ} \mathrm{C}$ is the ideal decrepitation temperature for processing the concentrate though $1050{ }^{\circ} \mathrm{C}$ has normally been used by several researchers for processing spodumene ores. At $1050{ }^{\circ} \mathrm{C}$, melting and agglomeration of spodumene with impurities are observed (Figure $7 \mathrm{~h}$ ). A closer look at a portion in Figure 7h (square " $\mathrm{A}$ ") confirms the melting and agglomeration (Figure 7i). We observe several regions of dark and light grey as well as dotted white regions with each coloration corresponding to a mineral phase which are fused together in Figure $7 \mathrm{i}$ due to melting. Specifically, spots "1" 2 " 4 " and "6" were identified in Figure 7i which corresponds to spodumene, amphibole, quartz and feldspars which were fused together. Tantalite and other minerals were also seen fused with some spodumene at other portions. 
Most investigations of lithium extraction from spodumene are performed at a decrepitation temperature of $1050{ }^{\circ} \mathrm{C}$, however, we advise $1000{ }^{\circ} \mathrm{C}$ as the ideal decrepitation temperature for this concentrate owing to the agglomeration at this temperature which can affect downstream processes and the extraction efficiency of lithium.

Most minerals were identified in the residues and thermal treatment did not have any major influence on their composition except melting and agglomeration of the particles at higher temperatures. A representative elemental composition as determined by EDS for samples treated at 900,950 and $1000{ }^{\circ} \mathrm{C}$ are indicated in Tables S18-S20. Though there was no major effect of thermal treatment on the mineral phases, ionic diffusion was observed in some of the residues at increased temperatures which becomes prominent at $1050{ }^{\circ} \mathrm{C}$. Due to this diffusion, the segregation of the feldspars into their individual minerals as well as differentiating them from the micas by EDS becomes a challenge since they appear to have similar elemental compositions. Table 5 shows some elemental associations with spodumene (spot "1"), amphiboles (spot "2") and representative composition of micas and feldspars (spot " 3 ", " 5 ", " 6 ") as a result of ionic diffusion between minerals at $1050{ }^{\circ} \mathrm{C}$. The composition of quartz, hematite, tantalite and apatite were not greatly affected regarding the ionic diffusion and are indicated at spots $4,7,8$ and 9, respectively.

Table 5. Atomic percentage of some mineral phases identified by SEM-EDS at $1050{ }^{\circ} \mathrm{C}$.

\begin{tabular}{|c|c|c|c|c|c|c|c|}
\hline Elements & Spot "1" & Spot "2" & $\begin{array}{l}\text { Spot " } 3 \text {, } \\
5 \text { and } 6 \text { " }\end{array}$ & Spot "4" & Spot "7" & Spot "8" & Spot "9" \\
\hline $\mathrm{O}$ & 64.3 & & 62.8 & 66.7 & 60.1 & 67.3 & 56.9 \\
\hline $\mathrm{Al}$ & 11.4 & 3.4 & 6.6 & & 0.4 & & \\
\hline $\mathrm{Si}$ & 23.1 & 19.5 & 24.3 & 33.3 & 0.6 & & \\
\hline $\mathrm{Fe}$ & 0.2 & 14.4 & 0.8 & & 38.9 & 1.9 & \\
\hline $\mathrm{Mg}$ & 0.2 & 3.9 & 0.3 & & 0.1 & & \\
\hline $\mathrm{Ca}$ & 0.1 & 1.7 & 0.5 & & & & 2.4 \\
\hline $\mathrm{Mn}$ & 0.1 & 0.2 & & & & 8.5 & 0.3 \\
\hline $\mathrm{Na}$ & 0.6 & 0.9 & 2.0 & & & & \\
\hline K & 0.2 & 0.8 & 2.7 & & & & \\
\hline $\mathrm{Ti}$ & & 0.3 & & & & & \\
\hline $\mathrm{F}$ & & & & & & & 7.9 \\
\hline $\mathrm{P}$ & & & & & & & 14.5 \\
\hline $\mathrm{Nb}$ & & & & & & 12.1 & \\
\hline $\mathrm{Ta}$ & & & & & & 10.3 & \\
\hline
\end{tabular}

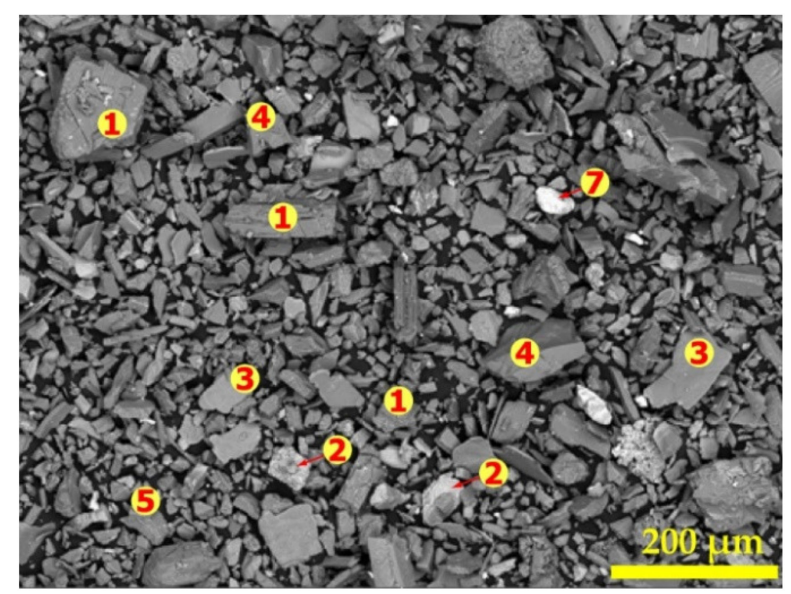

(a)

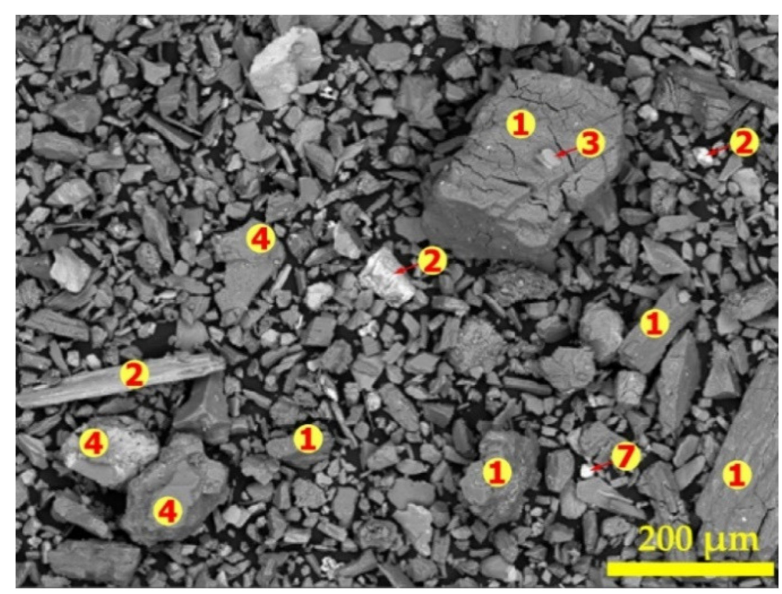

(b)

Figure 7. Cont. 


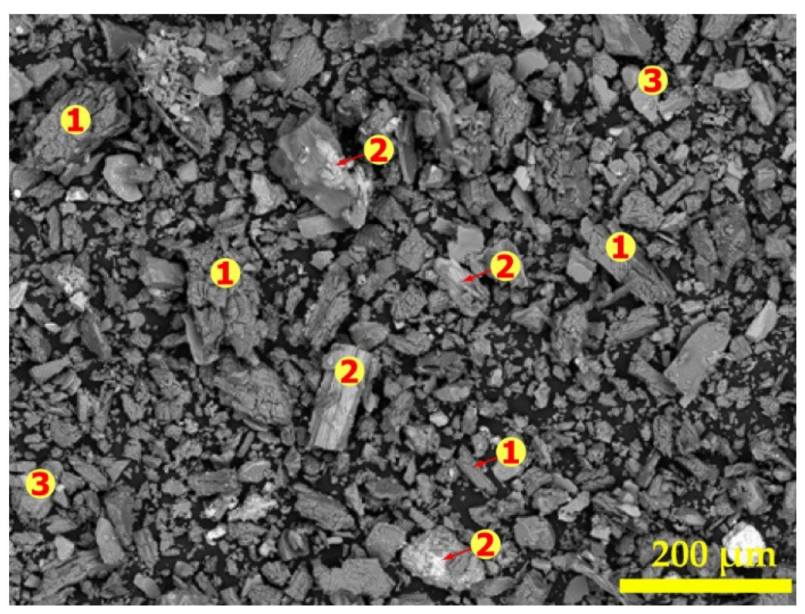

(c)

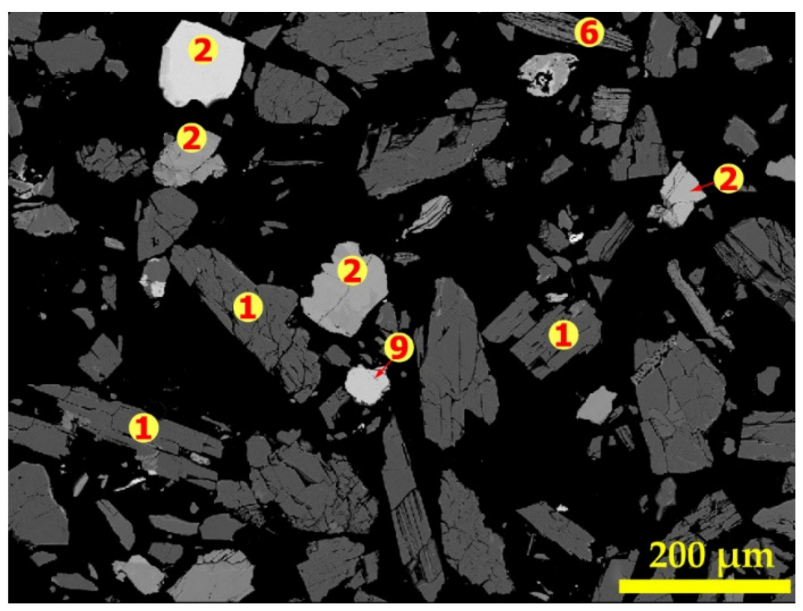

(e)

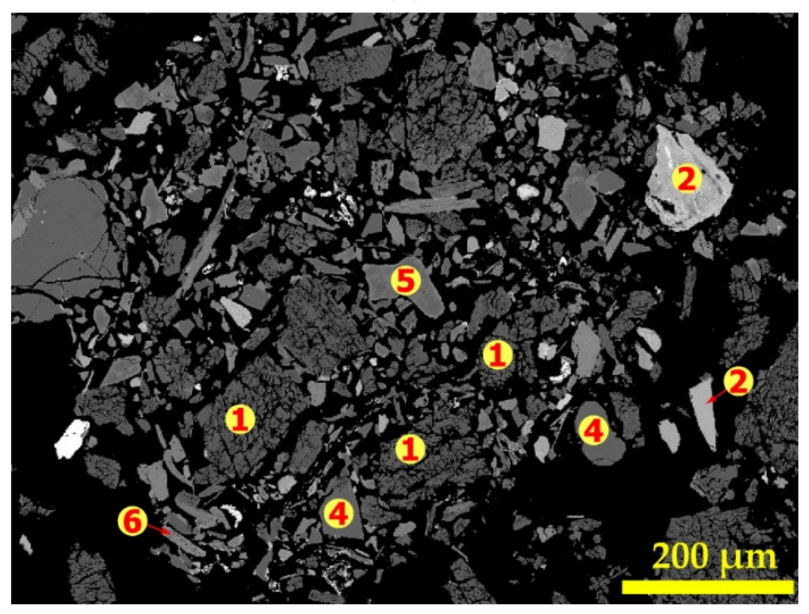

(g)

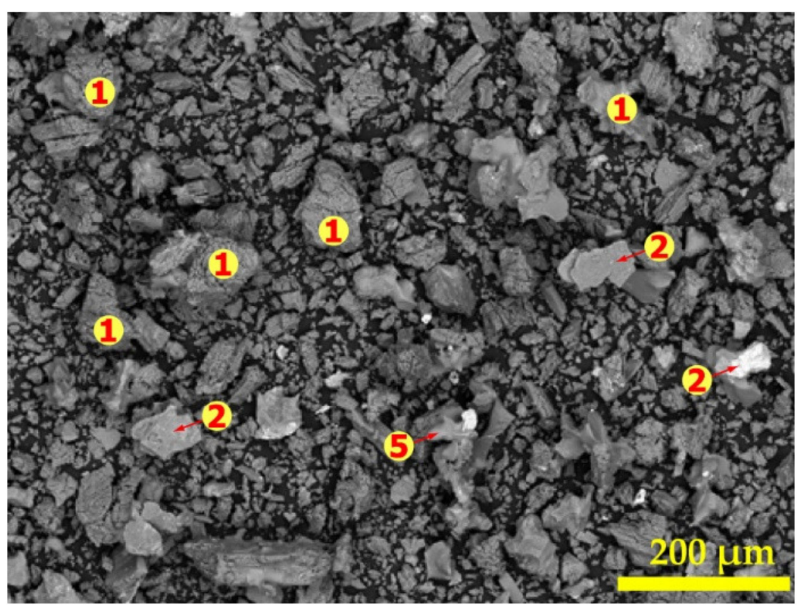

(d)

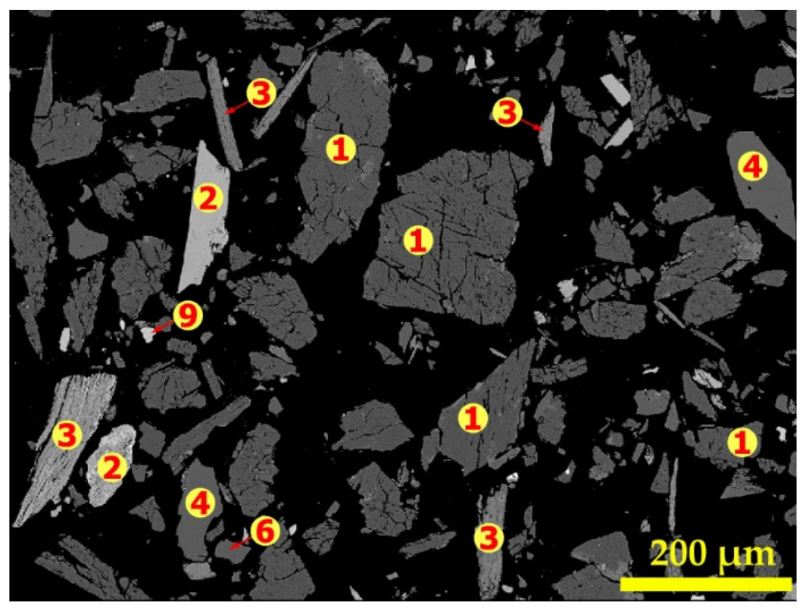

(f)

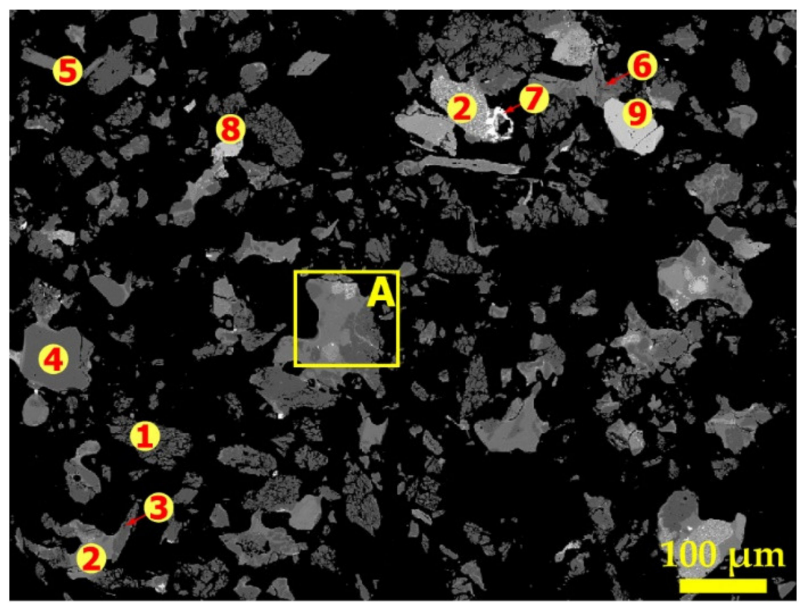

(h)

Figure 7. Cont. 


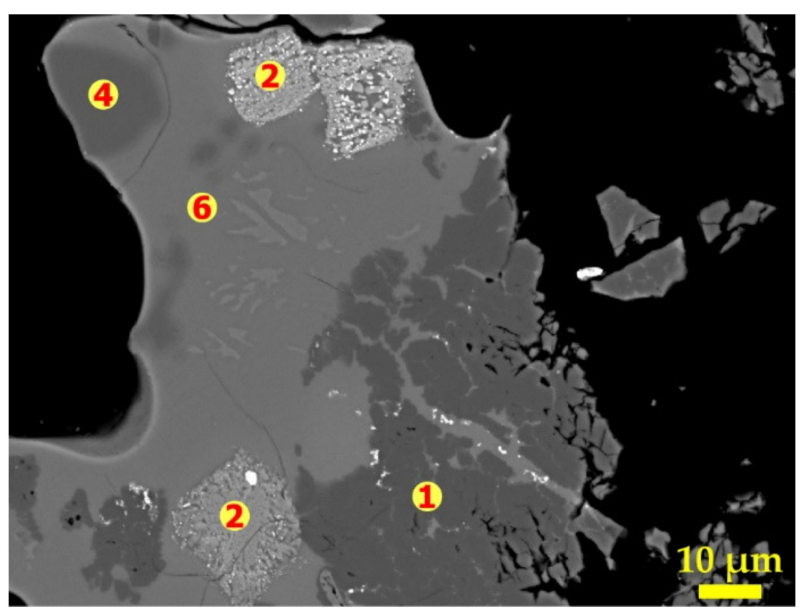

(i)

Figure 7. SEM and spot elemental determination of powdered (a-d) and polished sample (e-h) residues obtained after concentrate treatment in air at $900{ }^{\circ} \mathrm{C}(\mathbf{a}, \mathbf{e}), 950{ }^{\circ} \mathrm{C}(\mathbf{b}, \mathbf{f}), 1000{ }^{\circ} \mathrm{C}(\mathbf{c}, \mathbf{g}), 1050{ }^{\circ} \mathrm{C}(\mathbf{d}, \mathbf{h})$ and melting and agglomeration occurring in square " $\mathrm{A}^{\prime \prime}$ (i). The numbers (1 to 9) indicate the locations of the elemental determination.

\subsection{Conversion Extent of $\alpha$-Spodumene}

The extent of conversion of $\alpha$-spodumene to both $\gamma$ and $\beta$ was studied at temperatures ranging from 900 to $1000{ }^{\circ} \mathrm{C}$ as a function of residence time (7.5 to $480 \mathrm{~min}$ ). The result is presented in Figure 8. It is evident that the transformation increases with temperature and residence time. At $900{ }^{\circ} \mathrm{C}$, conversion of the $\alpha$-phase was observed after 60 min treatment which is characterized by peaks of $\gamma$ and $\beta$ in XRD diffractogram in Figure 9a. An almost full conversion was achieved at 975 and $1000^{\circ} \mathrm{C}$ as XRD patterns do not show the presence of $\alpha$-phase after 240 and $60 \mathrm{~min}$, respectively (Figure S9c,d). At $900{ }^{\circ} \mathrm{C}$, transformation increased slightly over time. Only $25 \%$ conversion was achieved even after $480 \mathrm{~min}, 17 \%$ of the transformed phase being the $\beta$-phase (Figure 8). After $480 \mathrm{~min}$ the $\alpha$-phase was still dominant indicating that the phase transformation is more sensitive to temperature than dwelling time. A sharp increase in conversion is observed by increasing the temperature a little above $900{ }^{\circ} \mathrm{C}\left(925^{\circ} \mathrm{C}\right)$. More than $60 \%$ transformation was attained after $480 \mathrm{~min}$. Few of the transformed phase $(17 \%)$ is due to the $\gamma$-phase and the majority $(50 \%)$ are the $\beta$-phase. Peaks of the initially dominant $\alpha$-phase gradually decreased whilst the $\beta$-phase increased with residence time (Figure S9a), confirming also increasing transformation with time. The higher experimental temperature required a shorter residence time for the transformation and vice versa. Further investigations at 1025 and $1050{ }^{\circ} \mathrm{C}$ also did not show any $\alpha$-phase in the XRD spectrum (Figure S9b,e).

\subsection{Evolution Extent of $\beta$-Spodumene}

The formation of $\beta$-spodumene is favored by increasing the temperature and residence time (Figure 10). The maximum formed at $900{ }^{\circ} \mathrm{C}$ is about $17 \%$ while almost $100 \%$ was achieved at $1050{ }^{\circ} \mathrm{C}$ after $60 \mathrm{~min}$. Temperature is observed to be the most sensitive parameter for the process and once the threshold temperature is attained, a few minutes of heating result in appreciable formation. The temperature of $1050{ }^{\circ} \mathrm{C}$ is found as the threshold temperature in this study for treating the concentrate; resulting in almost $100 \% \alpha$-conversion and $85 \% \beta$-formation in just $7.5 \mathrm{~min}$ respectively. This is seen in Figure $9 \mathrm{~b}$ where only $\gamma$ and $\beta$-phases are present in the diffractogram after $7.5 \mathrm{~min}$ of treatment. The threshold temperature for the process was also documented elsewhere [20,21]. Investigations by Peltosari et al. [10] and Salakjani et al. [22] revealed a comparatively higher temperature $\left(1100{ }^{\circ} \mathrm{C}\right)$ as the threshold for the $\beta$-phase formation. We suspect that the difference in temperatures reported in the literature and that presented in this study are due to different gangue concentrations in ores, the heat treatment process as well the nature of calibration applied to the furnace. Peltosari et al. [10] nor Salakjani et al. [22], however, gave detailed 
information on these parameters in order to confirm this speculation. Additionally, there is an influence due to particle size; a higher reaction rate at a lower particle size was observed by Peltosari et al. [10]. The particle size identified in this concentrate is, however, good enough to achieve considerable mineral liberation as well as a $\beta$-phase formation at a comparatively lower temperature.

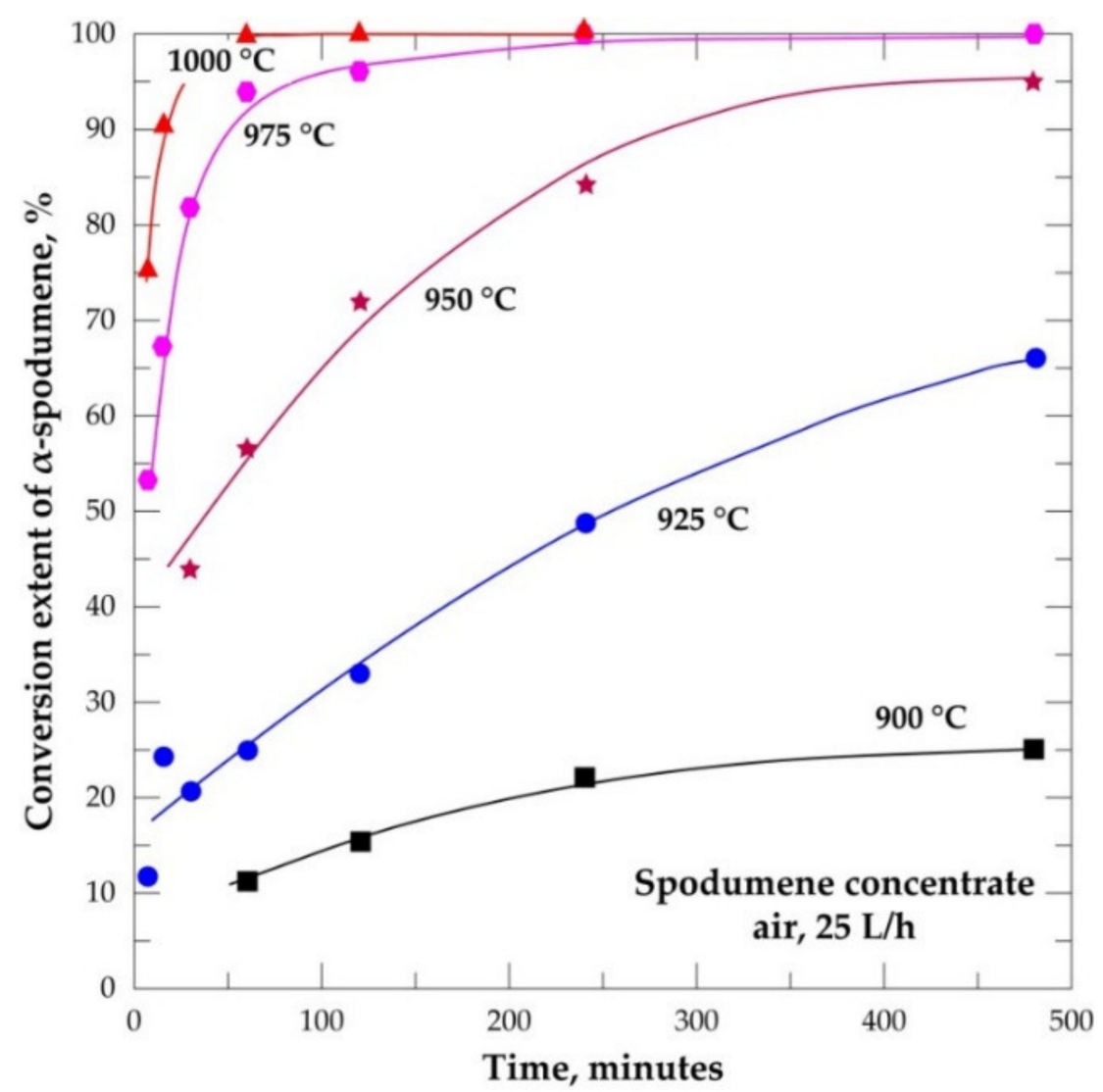

Figure 8. Conversion extent of $\alpha$-spodumene into $(\beta+\gamma)$ form during treatment of the concentrate between 900 and $1000{ }^{\circ} \mathrm{C}$ as a function of residence time.

\subsection{Evolution of the Relative $\gamma$-Spodumene}

Peaks of metastable $\gamma$-phase are seen in XRD diffractogram from the start of the experiment and persist throughout until after $60 \mathrm{~min}$ treatment at $1050{ }^{\circ} \mathrm{C}$ where it disappears. This phase might be formed at lower temperatures below the minimum temperature of this study as mentioned by Moore et al. [3] and Peltosaari et al. [10] who identified this phase at 800 and $896^{\circ} \mathrm{C}$ respectively. The present observation is in agreement with what was reported at $915^{\circ} \mathrm{C}$ by Abdullah et al. [11]. The peaks are not very intense compared to the other phases due to the continuous conversion into $\beta$-form as it is formed. Percent evolution of the $\gamma$-phase throughout the operating temperatures as a function of the residence time in this study is shown in Figure S10. About 23\% was the maximum quantity formed in this study at $975{ }^{\circ} \mathrm{C}$ after $120 \mathrm{~min}$ (Figure S2d), which is comparable to the maximum quantity identified by Abdullah et al. [11] at $1125^{\circ} \mathrm{C}$. Likewise, Moore et al. [3] and Peltosaari et al. [10] recorded $35 \%$ and $40 \%$ as the highest in their studies, respectively. According to Abdullah et al. [11] and Gasalla et al. [23], the quantity of this phase formed is influenced by the particle size of the feed as well as the heat treatment technique employed; finer particles impact amorphicity which easily recrystallizes into the $\gamma$-phase on heating compared to larger-sized particles. The heating rate employed also influences the quantity formed; slow heating rates form higher amounts due to the slow rate of conversion to the $\beta$-form. There was no major change in the quantity of this phase formed as a function of the residence time in the present work. This may be as a result of the constant heating 
rate which was maintained throughout the study, hence converting it to the $\beta$-form at the same rate. Though Moore et al. [3] indicated the importance of residence time on the transformation, they observed only a marginal $20 \%$ increase in this phase after increasing time from $45 \mathrm{~min}$ to $240 \mathrm{~min}$ at $981^{\circ} \mathrm{C}$.

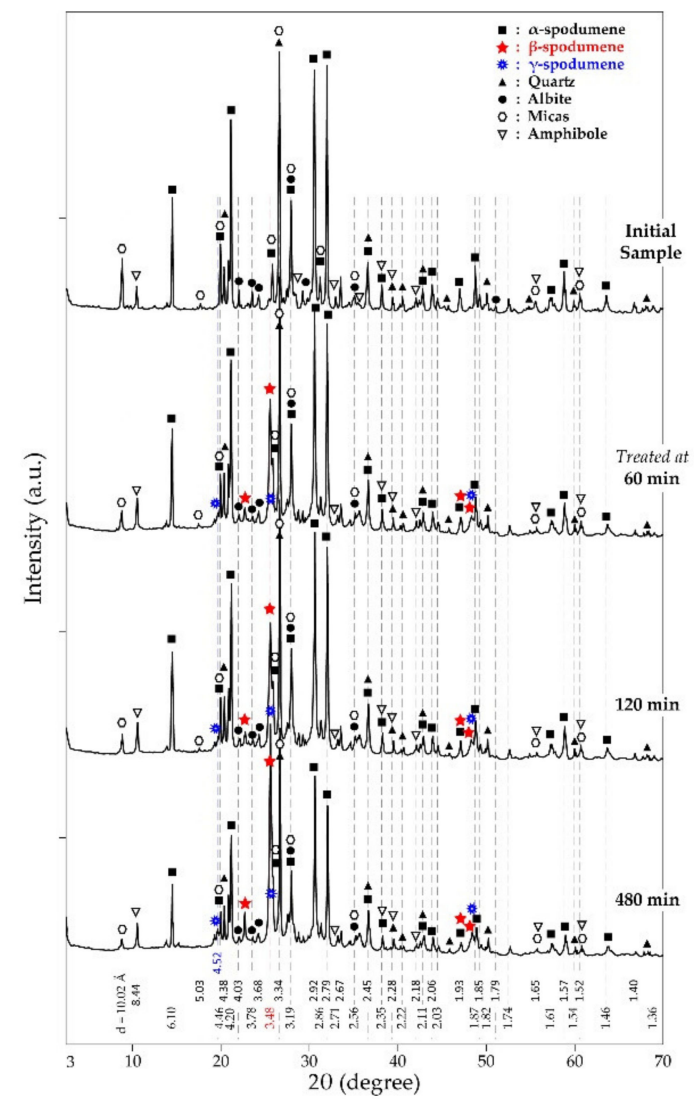

(a)

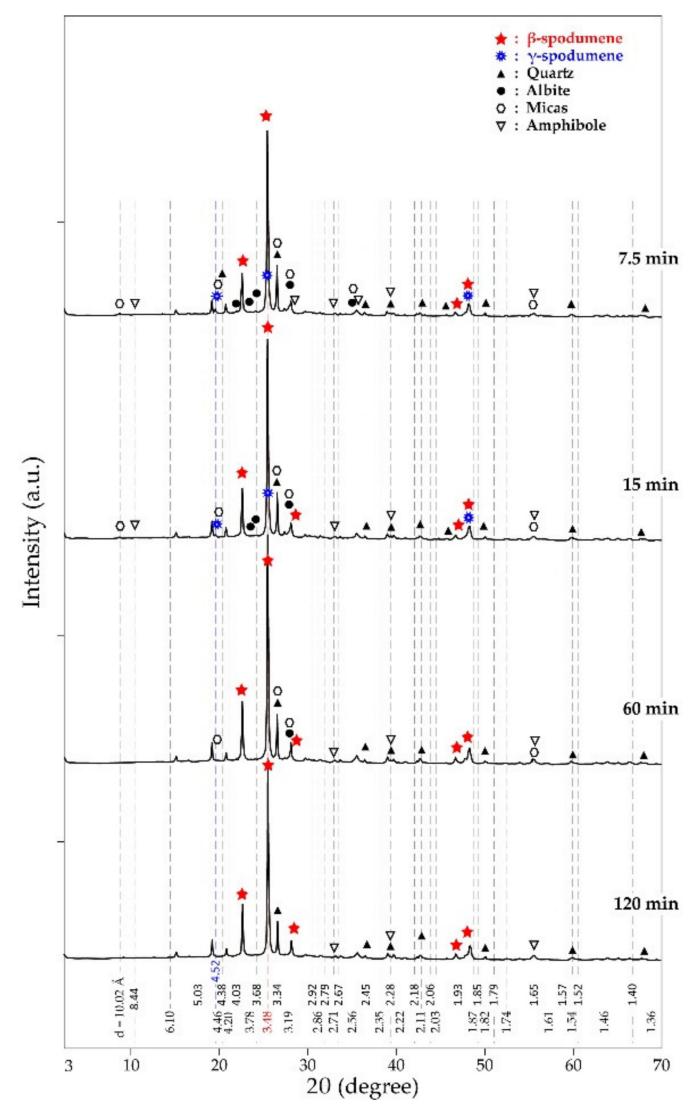

(b)

Figure 9. XRD patterns of residues obtained after concentrate treatment in air as a function of residence time at $900{ }^{\circ} \mathrm{C}(\mathbf{a})$ and $1050{ }^{\circ} \mathrm{C}(\mathbf{b})$.

It is interesting to note that, the shape of the curves in Figure S10 may predict the rate of its formation and conversion into the $\beta$-phase. There is a gentle rise and fall of the curve at lower residence time which becomes steeper with increasing residence time. This indicated a lower rate of formation and conversion at lower residence time and vice versa. From Figure 11, both $\gamma$ - and $\beta$-phases evolve from the onset of the experiment but their concentration varies considerably; the quantity of $\gamma$-phase being lower than the $\beta$-phase at all times. This observation is contrary to research by Moore et al. [3] who indicated that both phases occur in equal amounts with no preference of formation of one phase over the other. We also find that the quantity of each phase formed is temperature dependent with increasing temperature favoring the quantities evolved; which is also in opposition to their findings. At $975^{\circ} \mathrm{C}$, almost all the $\alpha$-phase had decayed and subsequent $\beta$-phase formation was solely dependent on the available $\gamma$-phase. Dessemond et al. [24] investigated the effect of this phase concomitant with the $\beta$-phase and its effect on lithium extraction. They indicated that its presence adversely affects the lithium extraction if its content is above $10 \%$, however, below it, its effect is minimal, and a typical industrial lithium recovery of $95 \%$ is attainable. This therefore calls for a closer look at the ideal temperature and residence time required for the porcess, paying attention to the economics, possible melting and agglomeration and its effects on downstream processes. 


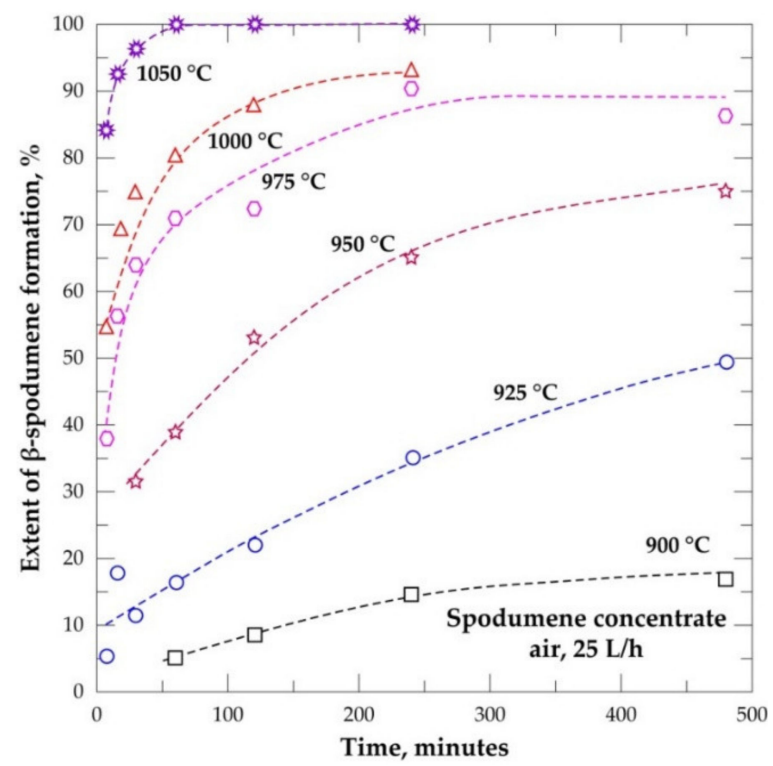

Figure 10. Spodumene formation during treatment of concentrate between 900 and $1050{ }^{\circ} \mathrm{C}$ as a function of residence time.

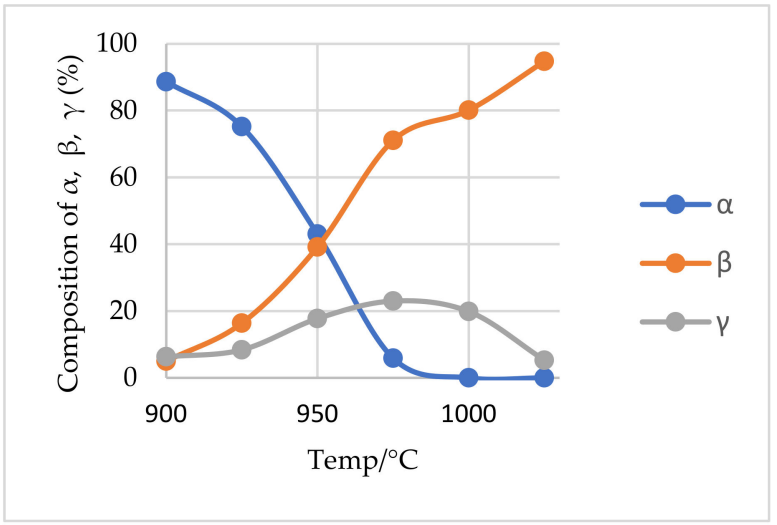

Figure 11. Percentage phase composition of $\alpha, \beta$ and $\gamma$ as a function of temperature after $60 \mathrm{~min}$ treatment.

\subsection{Phase Transformation and Kinetic Parameters}

The phase transformation of spodumene during thermal treatment was extensively studied by many researchers $[3,10,11]$ revealing $\alpha, \beta$ and $\gamma$ as the phases which are present during the process. The transition is generally known to follow the following pathways:

$$
\begin{gathered}
\alpha \stackrel{k_{1}}{\rightarrow} \gamma+\beta \\
\gamma \stackrel{k_{2}}{\rightarrow} \beta
\end{gathered}
$$

where $k_{1}$ and $k_{2}$ are the rate constants for $\alpha$ and $\gamma$ decay, respectively.

Thus, from Equation (1), $\alpha$-spodumene decays to form $\gamma$ and $\beta$ phases. The $\gamma$-phase which is formed finally transforms to the $\beta$-phase (Equation (2)). Previous studies have suggested a first-order kinetic model for the two transitions. We therefore apply this kinetic theory to both transitions to estimate the fitting kinetic parameters. From an integrated rate Equations of (1) and (2), it follows that:

$$
\ln \alpha_{t}=\ln \alpha_{o}-k_{1} \mathrm{t}
$$




$$
\ln \gamma_{t}=\ln \gamma_{o}-k_{2} \mathrm{t}
$$

where $\alpha_{o}$ and $\gamma_{o}$ are the initial concentration of $\alpha$ - and $\gamma$-phase; $\alpha_{t}$ and $\gamma_{t}$ are concentrations of $\alpha$ - and $\gamma$-phase at time $t$, respectively.

We estimate the rate constants for the decay processes $\left(k_{1}\right.$ and $\left.k_{2}\right)$ by plotting data in Tables S21 and S22 using Equations (3) and (4). The resulting $k_{1}$ and $k_{2}$ are indicated in Table 6 . These values are found to increase with increasing temperature and they confirm the sensitivity of the processes to temperature. The activation energy can be obtained from a linearized Arrhenius Equation (5):

$$
\ln k=\ln A-\frac{E_{a}}{R T}
$$

where $k$ is the rate constant; $A$, the pre-exponential factor; $E a$, the activation energy; $R$, the gas constant; $T$, the absolute temperature. The apparent activation energies obtained from the Arrhenius plots (Figure 12) for both decay processes using our data in Tables S23 and S24 are 655 and $731 \mathrm{~kJ} \mathrm{~mol}^{-1}$, respectively. Thus, a comparatively larger amount of energy is required for the decay of $\gamma$-spodumene in the second phase of the process than the decay of the $\alpha$-phase. This is expected due to the higher temperature required for the decay of $\alpha$-phase prior to the $\gamma$-decay. However, $\alpha$-decay occurs at a faster rate compared to $\gamma$-decay (Table 6). Estimated standard errors) for the regression for obtaining the activation energies are very minimal (0.1297 and 0.0489 respectively for $\alpha$ and $\gamma$ decay); suggesting a good fit and reliable activation energy values for a first-order kinetic model. We record lower apparent activation energy for $\alpha$-decay than reported in the literature [3]. Abdullah et al. [11] suggested that $\gamma$-phase may evolve either from amorphous or crystalline spodumene and suggested the following reaction pathways for the process;

$$
\begin{aligned}
& \text { Amorphous spodumene } \rightarrow \gamma \text {-spodumene } \rightarrow \beta \text {-spodumene } \\
& \text { Crystalline } \alpha \text {-spodumene } \rightarrow \gamma \text {-spodumene } \rightarrow \beta \text {-spodumene }
\end{aligned}
$$

Table 6. Reaction rate constants $k_{1}$ and $k_{2}$ estimated for $\alpha$ - and $\gamma$-decay, respectively.

\begin{tabular}{ccccccc}
\hline $\mathbf{T}^{\circ} \mathbf{C}$ & $\mathbf{9 0 0}$ & $\mathbf{9 2 5}$ & $\mathbf{9 7 5}$ & $\mathbf{1 0 0 0}$ & $\mathbf{1 0 2 5}$ & $\mathbf{1 0 5 0}$ \\
\hline$k_{1}\left(\mathrm{~min}^{-1}\right)$ & 0.0004 & 0.0019 & 0.0224 & 0.0054 & 0.0224 & 0.085 \\
$k_{2}\left(\mathrm{~min}^{-1}\right)$ & & & & 0.0048 & 0.0192 & 0.065 \\
\hline
\end{tabular}

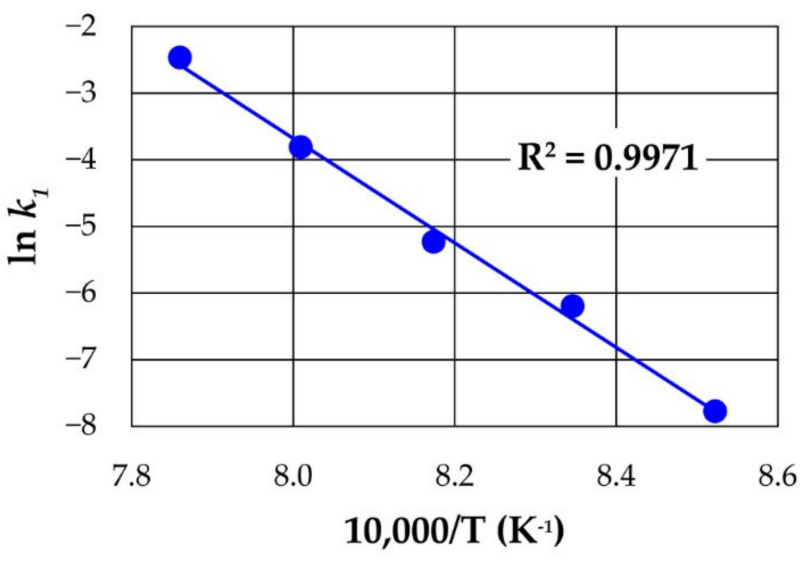

(a)

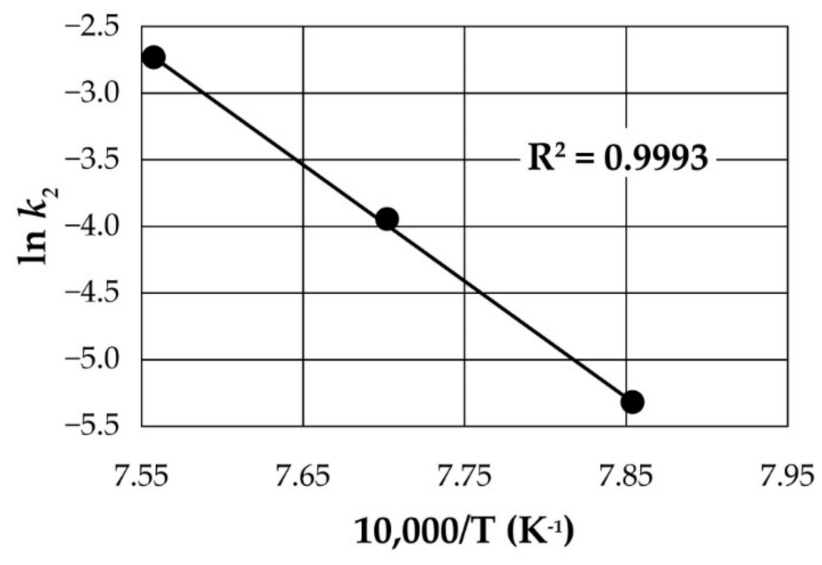

(b)

Figure 12. (a) ln $k_{1}$ against temperature (b) $\ln k_{2}$ against temperature employing first-order kinetic model rate constants of decay plotted in Arrhenius form. 
The path of the mechanism may influence the overall activation energy. They predicted low and high activation energies for (5) and (6), respectively. They indicated that finer particles introduce amorphicity, which easily crystalizes out with reduced activation energy. Comparing their particle size to what was used in the current study reveals that our sample is finer and more amorphous than theirs. This suggests that the evolution of the $\gamma$-phase from $\alpha$-spodumene in this study is from the amorphous phase rather than crystalline. Reaction path (5) is therefore suggested for this study and as a result, contributes to the lower activation energy recorded for $\alpha$-decay in this work than in previous studies.

\section{Conclusions}

The physicochemical characteristics of spodumene concentrate from the Pilbara region were studied. The $\mathrm{d} 50$ and $\mathrm{d} 80$ of the sample were obtained to be 57 microns and 113 microns, respectively. Particle diameter ranges from 10 to 200 microns with about $68 \%$ of the total volume being 80 microns in diameter. At these conditions, spodumene is well liberated at approximately $99 \%$, indicating that sufficient particle size reduction was achieved to enable further processing. Mineral phase identification by the analytical techniques employed in this study is consistent with each other for major minerals. The phase transformation of spodumene from 900 to $1050{ }^{\circ} \mathrm{C}$ and 7.5 to $480 \mathrm{~min}$ dwelling time was studied using XRD. $\alpha$ transformation was complete at 975 and $1000{ }^{\circ} \mathrm{C}$ whilst that of $\gamma$ occured at $1025^{\circ} \mathrm{C}$ and $1050{ }^{\circ} \mathrm{C}$ all at different treatment times. About $23 \%$ was the maximum quantity of $\gamma$-phase formed. We indicate $1050{ }^{\circ} \mathrm{C}$ as the threshold temperature for maximum $\beta$-phase formation. That notwithstanding, the process must be optimized since previous studies have indicated that the presence of less than $10 \% \gamma$-phase in the residue does not have a major adverse effect on lithium extraction efficiency. Should this study be valid, then we recommend $1000{ }^{\circ} \mathrm{C}$ thermal treatment for $60 \mathrm{~min}$ as an ideal decrepitation temperature for this concentrate considering the economics and quantity of $\gamma$-phase formed. However, if only a $\beta$-phase is required for industrial application, then a choice must be made at 1025 or $1050{ }^{\circ} \mathrm{C}$, paying attention to the time required for the transformation, as well as the melting, which occurs at $1050{ }^{\circ} \mathrm{C}$ and its effect on downstream processing. In view of these uncertainties, we recommend further investigation between these temperatures which leads to good lithium extraction efficiency on this material.

Applying first-order kinetic models to the two processes provides a satisfactory fit to the experimental data and yields kinetic parameters and apparent activation energies of 655 and $731 \mathrm{kJmol}^{-1}$, respectively for $\alpha$ - and $\gamma$-decay. SEM investigations reveal that, with increasing intensity of thermal treatments, spodumene grains undergo cracking, disintegration, followed by melting and agglomeration.

Supplementary Materials: The following are available online at https://www.mdpi.com/article/ 10.3390/ma14237423/s1, Figure S1: Spot analysis (a) and spectrum (b) of elemental composition of spodumene grain in concentrate, Figure S2: Spot analysis (a) and spectrum (b) of elemental composition of amphibole grain in concentrate, Figure S3: Spot analysis (a) and spectrum (b) of elemental composition of mica grain in concentrate, Figure S4: Spot analysis (a) and spectrum (b) of elemental composition of quartz grain in concentrate, Figure S5: Spot analysis (a) and spectrum (b) of elemental composition of albite grain in concentrate, Figure S6: Spot analysis (a) and spectrum (b) of elemental composition of hematite grain in concentrate, Figure S7: Spot analysis (a) and spectrum (b) of elemental composition of tantalite grain in concentrate, Figure S8: Spot analysis (a) and spectrum (b) of elemental composition of apatite grain in concentrate, Figure S9: XRD patterns of residues obtained during treatment of concentrate in air as a function of residence time at $925{ }^{\circ} \mathrm{C}(\mathrm{a}), 950{ }^{\circ} \mathrm{C}(\mathrm{b}), 975{ }^{\circ} \mathrm{C}$ (c), 1000 (d), $1025{ }^{\circ} \mathrm{C}$ (e), Figure S10: Evolution of the relative $\gamma$-spodumene content $[(\gamma /(\alpha+\beta+\gamma) * 100]$ during treatment as a function of temperature for residence times: (a) $7.5 \mathrm{~min}$, (b) $30 \mathrm{~min}$, (c) $60 \mathrm{~min}$ and (d) $120 \mathrm{~min}$, Table S1: Calculated elemental assay of major elements by MLA and their corresponding oxides, Table S2: MLA data for degree of mineral liberation in concentrate used to generate Figure 4, Table S3: Standard deviation on atomic percent of elemental composition of spodumene in concentrate, Table S4: Standard deviation on atomic percent of elemental composition of amphiboles in concentrate, Table S5: Standard deviation 
on atomic percent of elemental composition of quartz in concentrate, Table S6: Standard deviation on atomic percent of elemental composition of albite in concentrate, Table S7: Standard deviation on atomic percent of elemental composition of mica in concentrate, Table S8: Standard deviation on atomic percent of elemental composition of hematite in concentrate, Table S9: Standard deviation on atomic percent of elemental composition of apatite in concentrate, Table S10: Raw data of spodumene grain generated by SEM-EDS for spectrum 1, Table S11: Raw data of amphibole grain generated by SEM-EDS for spectrum 2, Table S12: Raw data of mica grain generated by SEM-EDS for spectrum 5, Table S13: Raw data of quartz grain generated by SEM-EDS for spectrum 13, Table S14: Raw data of albite grain generated by SEM-EDS for spectrum 3, Table S15: Raw data of hematite grain generated by SEM-EDS for spectrum 1, Table S16: Raw data of tantalite grain generated by SEM-EDS for spectrum 3, Table S17: Raw data of apatite grain generated by SEM-EDS for spectrum 5, Table S18: Atomic percentage of some mineral phases identified by SEM-EDS at $900{ }^{\circ} \mathrm{C}$, Table S19: Atomic percentage of some mineral phases identified by SEM-EDS at $950{ }^{\circ} \mathrm{C}$, Table S20: Atomic percentage of some mineral phases identified by SEM-EDS at $1000^{\circ} \mathrm{C}$, Table S21: Data for determination of apparent rate constants, $\mathrm{k} 1$ for $\alpha$-decay from Equation (3), Table S22: Data for determination of apparent rate constants, k2 for $\gamma$-decay from Equation (4), Table S23: Data for calculating apparent activation energy for $\alpha$-decay from Equation (5), Table S24: Data for calculating apparent activation energy for $\gamma$-decay from Equation (6).

Author Contributions: Conceptualization, A.C., N.K. and A.Y.F.; writing-original draft preparation and writing-review and editing, A.C., N.K. and J.V.; supervision, A.C. and N.K.; Methodology and analysis for XRD, D.B.; Methodology analysis and data acquisition funding acquisition for MLA, H.H. All authors have read and agreed to the published version of the manuscript.

Funding: This work was supported by the French National Research Agency through the national program "Investissements d'avenir" with the reference ANR-10-LABX-21-RESSOURCES21.

Institutional Review Board Statement: Not applicable.

Informed Consent Statement: Not applicable.

Data Availability Statement: The data presented in this study are available upon request to the corresponding author.

Conflicts of Interest: The authors declare no conflict of interest.

\section{References}

1. Bradley, D.C.; McCauley, A.D.; Stillings, L.M. Mineral-Deposit Model for Lithium-Cesium-Tantalum Pegmatites; U.S. Geological Survey: Reston, VA, USA, 2017.

2. Pickles, C.A.; Marzoughi, O. Thermodynamic modelling of spodumene decrepitation. Miner. Process. Extr. Metall. Trans. Inst. Min. Metall. 2020, 1-15. [CrossRef]

3. Moore, L.R.; Mann, J.P.; Montoya, A.; Haynes, B.S. In situ synchrotron XRD analysis of the kinetics of spodumene phase transitions. Phys. Chem. Chem. Phys. 2018, 20, 10753-10761. [CrossRef] [PubMed]

4. Salakjani, N.K.; Singh, P.; Nikoloski, A.N. Production of Lithium-A Literature Review Part 1: Pretreatment of Spodumene. Miner. Process. Extr. Metall. Rev. 2020, 41, 335-348. [CrossRef]

5. Yonghua, D.; Lishi, M.; Ping, L.; Yong, C. First-principles calculations of electronic structures and optical, phononic, and thermodynamic properties of monoclinic $\alpha$-spodumene. Ceram. Int. 2017, 43, 6312-6321. [CrossRef]

6. Arlt, T.; Angel, R. Displacive phase transitions in C-centred clinopyroxenes: Spodumene, $\mathrm{LiScSi}_{2} \mathrm{O}_{6}$ and $\mathrm{ZnSiO}_{3}$. Phys. Chem. Miner. 2000, 27, 719-731. [CrossRef]

7. Moore, R.L.; Haynes, B.S.; Montoya, A. Effect of the Local Atomic Ordering on the Stability of $\beta$-Spodumene. Inorg. Chem. 2016, 55, 6426-6434. [CrossRef]

8. Li, C.-T.; Peacor, D.R. The crystal structure of LiAlSi2O6-II (“ $\beta$ spodumene”). Z. Krist. Mater. 1968, 126, 46-65. [CrossRef]

9. Fosu, A.Y.; Kanari, N.; Vaughan, J.; Chagnes, A. Literature Review and Thermodynamic Modelling of Roasting Processes for Lithium Extraction from Spodumene. Metals 2020, 10, 1312. [CrossRef]

10. Peltosaari, O.; Tanskanen, P.; Heikkinen, E.-P.; Fabritius, T. $\alpha \rightarrow \gamma \rightarrow \beta$-phase transformation of spodumene with hybrid microwave and conventional furnaces. Miner. Eng. 2015, 82, 54-60. [CrossRef]

11. Abdullah, A.A.; Oskierski, H.C.; Altarawneh, M.; Senanayake, G.; Lumpkin, G.; Dlugogorski, B.Z. Phase transformation mechanism of spodumene during its calcination. Miner. Eng. 2019, 140, 105883. [CrossRef]

12. Salakjani, N.K.; Singh, P.; Nikoloski, A.N. Acid roasting of spodumene: Microwave vs. conventional heating. Miner. Eng. 2019, 138, 161-167. [CrossRef] 
13. Rosales, G.D.; Resentera, A.C.J.; Gonzalez, J.A.; Wuilloud, R.G.; Rodriguez, M.H. Efficient extraction of lithium from $\beta$-spodumene by direct roasting with $\mathrm{NaF}$ and leaching. Chem. Eng. Res. Des. 2019, 150, 320-326. [CrossRef]

14. Rosales, G.D.; Ruiz, M.D.C.; Rodriguez, M.H. Novel process for the extraction of lithium from $\beta$-spodumene by leaching with HF. Hydrometallurgy 2014, 147, 1-6. [CrossRef]

15. Barbosa, L.I.; Valente, G.; Orosco, R.P.; González, J.A. Lithium extraction from $\beta$-spodumene through chlorination with chlorine gas. Miner. Eng. 2014, 56, 29-34. [CrossRef]

16. Barbosa, L.I.; González, J.A.; del Carmen Ruiz, M. Extraction of lithium from $\beta$-spodumene using chlorination roasting with calcium chloride. Thermochim. Acta 2015, 605, 63-67. [CrossRef]

17. Aylmore, M.G.; Merigot, K.; Rickard, W.D.A.; Evans, N.J.; Mcdonald, B.J.; Spitalny, P. Assessment of a spodumene ore by advanced analytical and mass spectrometry techniques to determine its amenability to processing for the extraction of lithium. Miner. Eng. 2018, 119, 137-148. [CrossRef]

18. Fandrich, R.; Gu, Y.; Burrows, D.; Moeller, K. Modern SEM-based mineral liberation analysis. Int. J. Miner. Process. 2007, 84, 310-320. [CrossRef]

19. $\mathrm{Gu}, \mathrm{Y}$. Automated Scanning Electron Microscope Based Mineral Liberation Analysis. An Introduction to JKMRC/FEI Mineral Liberation Analyser. J. Miner. Mater. Charact. Eng. 2003, 02, 33-41. [CrossRef]

20. Tian, Q.; Chen, B.; Chen, Y.; Ma, L.; Shi, X. Roasting and leaching behavior of spodumene in sulphuric acid process. Xiyou Jinshu Chin. J. Rare Met. 2011, 35, 118-123. [CrossRef]

21. White, G.D.; McVay, T.N. Some Aspects Of The Recovery Of Lithium From Spodumene; Oak Ridge National Laboratory: Oak Ridge, TN, USA, 1958.

22. Salakjani, N.K.; Singh, P.; Nikoloski, A.N. Mineralogical transformations of spodumene concentrate from Greenbushes, Western Australia. Part 1: Conventional heating. Miner. Eng. 2016, 98, 71-79. [CrossRef]

23. Gasalla, H.J.; Aglietti, E.F.; Lopez, J.M.P.; Pereira, E. Changes in physicochemical properties of $\alpha$-spodumene by mechanochemical treatment. Mater. Chem. Phys. 1987, 17, 379-389. [CrossRef]

24. Dessemond, C.; Soucy, G.; Harvey, J.P.; Ouzilleau, P. Phase transitions in the $\alpha-\gamma-\beta$ spodumene thermodynamic system and impact of $\gamma$-spodumene on the efficiency of lithium extraction by acid Leaching. Minerals 2020, 10, 519. [CrossRef] 